Vietnam Journal of Earth Sciences, 38(4), 345-355, DOI: 10.15625/0866-7187/38/4/8797

Vietnam Academy of Science and Technology
(VAST)

\title{
Effect of silicic acid on aggregation of hydrous ferric oxide
}

\author{
Nguyen Ngoc Minh*,1,2, Flynn Picardal ${ }^{1}$ \\ ${ }^{1}$ School of Public and Environmental Affairs, Indiana University, MSBII, Walnut Grove Ave, Bloomington, USA \\ ${ }^{2}$ Faculty of Environmental Science, VNU University of Science, Vietnam National University \\ Received 5 July 2016. Accepted 13 October 2016
}

\begin{abstract}
Colloidal properties of hydrous ferric oxide (HFO) have received much attention due to their environmental relevance. In this study, aggregation of HFO was determined by time-resolved dynamic light scattering and test tube experiments, evaluating surface charge via zeta potential $(\zeta)$ measurements. The silicic acid charge varies with protonation and deprotonation at different $\mathrm{pH}$ levels. As an adsorbing species, silicic acid could modify surface charge and affect the colloidal stability of HFO. Electrophoretic experiments revealed that silicic acid lowered particle $\zeta$, decreased the isoelectric point (iep), and allowed HFO to aggregate at a lower pH. Reversal of charge was observed at $\mathrm{pH} 7.5,7.0,6.4$, and 6.2 for silicic acid concentrations of $0,0.5,1.0$ and $1.5 \mathrm{mM}$, respectively. By demonstrating that silicic acid shifts the iep of HFO to lower $\mathrm{pH}$ values, results indicate that silicic acid can change the aggregation properties of HFO. Both light scattering and test tube experiments revealed a "peak aggregation" at $\mathrm{pH}$ 5.5-7.5 in the presence of silicic acid. As this $\mathrm{pH}$ range is typical for many aqueous systems and soils, we conclude that silicic acid likely plays an important role in HFO transport in water and accumulation of particulate HFO in soil horizons.
\end{abstract}

Keyworks: Silicic acid, hydrous ferric oxide, surface charge, aggregation.

C2016 Vietnam Academy of Science and Technology

\section{Introduction}

Hydrous ferric oxides (HFO) are poorly crystalline forms of $\mathrm{Fe}(\mathrm{III})$ that are often found in various natural environments including marine systems and soils (Towe and Bradley, 1967; Combes et al., 1989; Cornell and Schwertmann, 1996; Spadini et al., 2003). These minerals can be formed as initial products of precipitation from oxygenated,

*Corresponding author, Email: minhnn@vnu.edu.vn
Fe-rich, aqueous solutions, or by bacteria, either as a result of a metabolic activity or passive adsorption of dissolved $\mathrm{Fe}$, followed by nucleation reactions (Fortin and Langley, 2005). In an aqueous solution, HFO is hydrated, and $\mathrm{Fe}-\mathrm{OH}$ groups become chemically reactive. The charge on the HFO's surface, established by protonation or deprotonation of the $\mathrm{Fe}-\mathrm{OH}$ groups, depends on $\mathrm{pH}$ of the solution (Cornell and Schwertmann, 1996; Davis et al., 2002; Li et al., 2016). The nature and the extent of the 
Nguyen Ngoc Minh, Flynn Picardal/Vietnam Journal of Earth Sciences 38 (2016)

charge is a known factor governing the colloidal properties of HFO. The isoelectric point (iep), characterized as the $\mathrm{pH}$ at which the positive and negative charges of a given compound are equal, has been widely used to describe the aggregation properties of $\mathrm{Fe}$ oxides in general, and HFO in particular. HFO is expected to coagulate at $\mathrm{pH}$ levels near its iep, even at low ionic strengths, and to disperse at $\mathrm{pH}$ levels distant from the iep (Cornell and Schwertmann, 1996). Numerous studies state that HFO surface adsorption of anions or dissolved organic matter from its surrounding solution might lead to a decrease of the HFO iep, modifying aggregation properties. However, the effect of silicic acid, one of the most common solutes in the soil solution, has not yet been reported.

In nature, silicic acid is often found in monomeric form $\left(\mathrm{Si}(\mathrm{OH})_{4}\right)$, which can be either protonated or deprotonated, and can also condense to a variable extent, potentially yielding many dissolved species of polymeric silicic acids (Iler, 1979; Dove and Rimstidt, 1994) and nanocolloidal silica (Icopini et al., 2005) coexisting in equilibrium. The prevalence of each of these species, as well as their degree of protonation or deprotonation and resultant charge, depends primarily on $\mathrm{pH}$, but is also influenced by other factors such as ionic strength (Icopini et al., 2005) and temperature (Rothbaum and Rohde, 1979). The monomer is found in most natural waters (Dove, 1995; Dietzel, 2000). In soils, silicic acid can be found in both monomeric and polymeric forms (Wonisch et al., 2008). Concentrations can reach up to $1.99 \mathrm{mM}$ (Karathanasis, 2002), but are more commonly observed from ca 0.1 to $0.6 \mathrm{mM}$ (Epstein, 2001; Sommer et al., 2006). Silicic acid fluxes could presumably affect soil stability and cotransport of contaminants with HFO by changing HFO colloidal properties.

Earlier research has applied time-resolved dynamic light scattering (DLS), which quantifies the hydrodynamic diameter of particles in suspension, to monodisperse model colloids such as latex microspheres (Holthoff et al., 1996) and clay colloids (Kretzschmar et al., 1998; Mori et al., 2001). As reported by Cornell and Schwertmann (1996) and Pike and Abbiss (1997), this method can also be effective with large particles possessing a non-spherical shape.

In this study, a synthesized HFO sample was used for characterization of aggregation under the effect of silicic acid. DLS and test tube experiments were combined to examine particle size evolution and aggregation kinetics of HFO under the effect of silicic acid as functions of $\mathrm{pH}$. Because particle surface charge is the most important parameter for

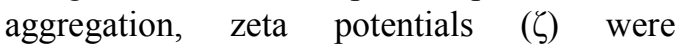
investigated to examine the effect of adsorption of silicic acid on surface charge properties and its correlation with the colloidal stability of HFO.

\section{Materials and methods}

\subsection{Materials}

An amount of $68 \mathrm{~g} \mathrm{FeCl}_{3} \cdot 6 \mathrm{H}_{2} \mathrm{O}$ from Sigma (USA) was dissolved in $600 \mathrm{~mL}$ of sterile deionized water. Sterile $5 \mathrm{M} \mathrm{NaOH}$ was added dropwise to the ferric chloride solution until the $\mathrm{pH}$ of the HFO suspension was stable at $\mathrm{pH}$ 7. The HFO suspension was poured into centrifuge bottles and centrifuged at $4^{\circ} \mathrm{C}$ for $20 \mathrm{~min}$, after which the supernatant was poured off and discarded. The HFO precipitates were washed 3 times with autoclaved water. HFO precipitates were resuspended in $500 \mathrm{~mL}$ autoclaved deionized water to make an HFO suspension at the concentration of $1 \mathrm{mg} \mathrm{mL}^{-1}$. Transmission electron microscopy images, captured using a JEOL 1010 TEM (USA), revealed aggregates of uniform HFO nanoparticles with an approximate elementary particle diameter of $10 \mathrm{~nm}$ (Figure 1). 
Vietnam Journal of Earth Sciences, 38(4), 345-355
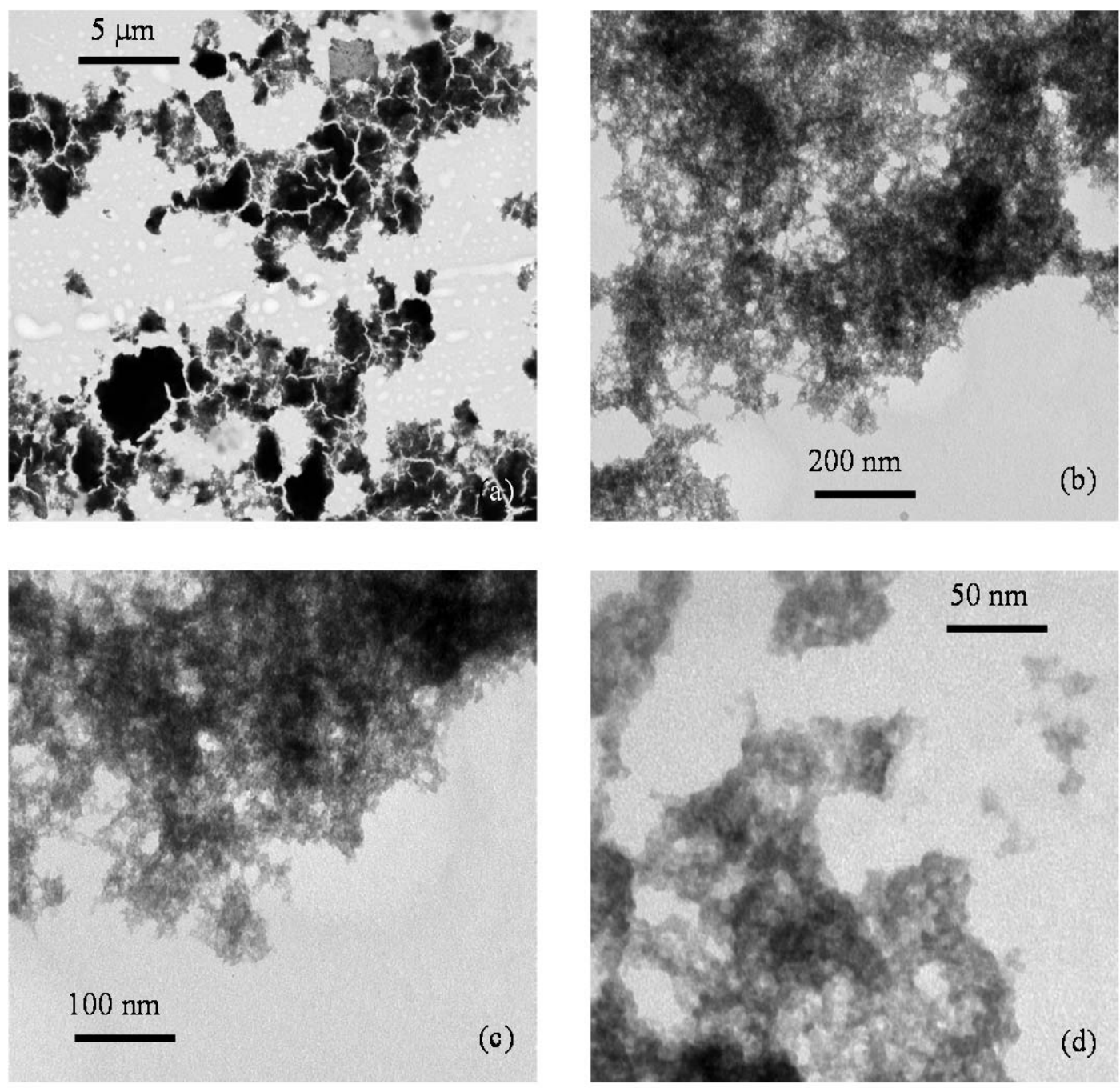

Figure 1. TEM image showing particles/clusters of HFO at different magnifications: (a) 1:2000, (b) 1:50,000; (c) $1: 100,000$ and (d) 1:200,000

Solutions for the evaluation of silicic acid effects were prepared by dissolving $20 \mathrm{~g}$ of pure silica gel with a particle size of $0.15 \mathrm{~mm}$ (Fisher Scientific Company, USA) in $200 \mathrm{~mL}$ deionized water by stirring at $70^{\circ} \mathrm{C}$ for $3 \mathrm{~d}$. The obtained bulk solution was kept for one week at room temperature and passed through a $0.45 \mu \mathrm{m}$ pore-size cellulose acetate filter. $\mathrm{Si}$ in the resultant filtrate was quantified by the molybdate blue method with a UV-Vis spectrophotometer (L-VIS-400, Labnics Company, USA), and then diluted to $2.0 \mathrm{mM}$.

\subsection{Methods}

\subsubsection{Zeta potential measurements}

The $\zeta$ for silicic acid and its mixtures with $\mathrm{HFO}$ as functions of $\mathrm{pH}$ and ionic strength were determined. As silicic acid may partially occur in polymeric forms with nano-sized 
Nguyen Ngoc Minh, Flynn Picardal/Vietnam Journal of Earth Sciences 38 (2016)

particles, the $\zeta$ of the particulates can be measured using a combination of laser Doppler velocimetry and phase analysis light scattering (Hunter, 1981). The $\zeta$ of silicic acid was examined at silicic acid concentrations of $0.5,1.0$, and $1.5 \mathrm{mM}$ over a $\mathrm{pH}$ range of $\sim 2$ to $\sim 12$. The $\mathrm{pH}$ of these solutions was adjusted to targeted values by dropwise addition of either $0.5 \mathrm{M} \mathrm{HCl}$ or $0.5 \mathrm{M} \mathrm{NaOH}$ solution. Each $1 \mathrm{~mL}$ of the $\mathrm{NaCl}$ solution was mixed with $2.5,5.0$, and $7.5 \mathrm{~mL}$ of $2 \mathrm{mM}$ silicic acid suspension (prepared as described above) and filled with deionized water to a final volume of $10 \mathrm{~mL}$. Final silicic acid concentrations of the obtained suspensions were $0.5,1.0$, and $1.5 \mathrm{mM}$. A subsample of $1.0 \mathrm{~mL}$ was then directly transferred into a DTS1070-folded capillary cell. $\zeta$ was measured in triplicate using a Malvern Zetasizer Nano ZS (UK).

In experiments measuring the $\zeta$ of the HFO suspensions as a function of $\mathrm{pH}, \zeta$ was determined at silicic acid concentrations of 0 , $0.5,1.0$, and $1.5 \mathrm{mM}$ in a $\mathrm{pH}$ range of $\sim 2$ to 12. Each $1 \mathrm{~mL}$ of HFO suspension (1 $\mathrm{mg}$ $\mathrm{mL}^{-1}$ ) was mixed with $1.25,2.5$, or $5.0 \mathrm{~mL}$ of $2.0 \mathrm{mM}$ silicic acid and then transferred into a plastic tube. Using different ratios of $0.5 \mathrm{M}$ $\mathrm{NaCl}, \mathrm{HCl}$, and $\mathrm{NaOH}$ and dilution with DI $\mathrm{H}_{2} \mathrm{O}$ as described above, we obtained different targeted $\mathrm{pH}$ values from $\sim 2$ to $\sim 12$ at the same ionic strength (IS) of $0.05 \mathrm{M}$. In experiments measuring $\zeta$ as a function of IS, suspensions were prepared similarly, but additions of $\mathrm{NaCl}$ were varied to produce the appropriate range of IS and $\mathrm{pH}$ 6. In the obtained suspensions, the final HFO concentration was $0.1 \mathrm{mg} \mathrm{mL}^{-1}$, whereas silicic acid concentrations were 0.25 , 0.5 , and $1.0 \mathrm{mM}$. A subsample of $1.0 \mathrm{~mL}$ was then directly transferred into a DTS1070folded capillary cell and $\zeta$ was measured in triplicate with the Malvern Zetasizer.

\subsubsection{Dynamic light scattering}

Suspensions of silicic acid and HFO at different $\mathrm{pHs}$ and ionic strengths were prepared in the same manner as those used for $\zeta$ determination (see 2.2.1). Hydrodynamic diameters of particulates in suspensions of silicic acid and HFO at different $\mathrm{pH}$ and IS values were examined according to Kretzschmar et al. (1998) using a Malvern Zetasizer Nano ZS (UK). The detector was positioned at an angle of $173^{\circ}$ to collect back scatter signals. In order to observe the evolution of HFO aggregates (changes in hydrodynamic diameter of particles in suspension, $d_{h}$ ) over time, the mean size was calculated by averaging $d_{h}$ values (nm) obtained each minute. These averages were plotted over a period of $20 \mathrm{~min}$.

\subsubsection{Colloidal stability in test tube experiments}

Colloidal stability of the HFO in the presence of the silicic acid as a function of $\mathrm{pH}$ was evaluated in plastic test tubes following the procedure of Lagaly et al. (1997). Using procedures similar to those described in 2.2.1, $0.2 \mathrm{mg} \mathrm{mL}^{-1}$ HFO suspensions were prepared over a target $\mathrm{pH}$ range and silicic acid concentrations of 0.0 to $1.4 \mathrm{mM}$. The suspensions were vortexed for $60 \mathrm{~s}$ to maximize particle dispersion and then held statically for 24 hours. An amount of $3 \mathrm{~mL}$ of each suspension was sampled from the surface of the suspension. The transmittance $(\% \mathrm{~T})$ was determined using a UV-VIS spectrophotometer (Shimadzu, UV-2101PC) at a wavelength of $380 \mathrm{~nm}$ and then converted into HFO amount in suspension (in \%).

\section{Results}

\subsection{Surface charge of silicic acid suspensions}

Our silicic acid solution included monomeric and/or polymeric forms in true solution, in addition to nanoparticulate polymers able to pass through a $0.45 \mu \mathrm{m}$ filter. Our $\zeta$ measurements for silicic acid are 
Vietnam Journal of Earth Sciences, 38(4), 345-355

likely primarily those of the nanoparticulate silicic acid polymers. The $\mathrm{pH}$ dependence of $\zeta$ at different silicic acid concentrations is depicted in Figure 2. At $\mathrm{pH}<6$, the nearneutral surface charge was observed at all three concentrations of silicic acid and $\zeta$ was maintained near $0 \mathrm{mV}$. For the silicic acid concentration of $0.5 \mathrm{mM}$, a substantial decrease in $\zeta$ occurred at $\mathrm{pH} 6.0$ to 7.5 , with the minimum $\zeta$ value of $-18.5 \mathrm{mV}$ found at $\mathrm{pH}$ 7.5. With a change in $\mathrm{pH}$ from 7.5 to 9.0 , the surface charge became less negative and $\zeta$ increased from -18.5 to $-2.0 \mathrm{mV}$. For silicic acid concentrations of 1.0 and $1.5 \mathrm{mM}$, decreases in $\zeta$ were observed at $\mathrm{pH}$ from 6 to 9 , in which minimum values of $\zeta$ were -20.0 and $-22.0 \mathrm{mV}$, found at $\mathrm{pH} 8.6$ and 9.0, respectively. At $\mathrm{pH}>9$, increases in $\zeta$ were found for silicic acid at both concentrations of 1.0 and $1.5 \mathrm{mM}$.

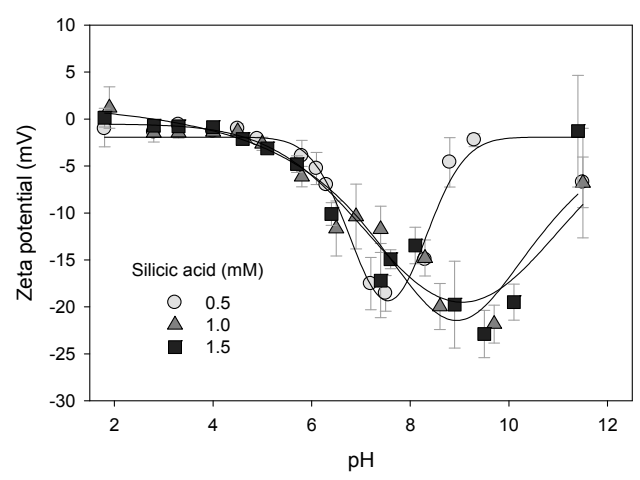

Figure 2. Zeta potential measured for silicic acid at concentrations of $0.5,1.0$, and $1.5 \mathrm{mM}$ as a function of $\mathrm{pH}$ in the presence of $0.05 \mathrm{M} \mathrm{NaCl}$ as the background electrolyte. Mean values with standard deviations appear as error bars of zeta potential

\subsection{Surface charge and aggregation of silicic acid - HFO suspensions}

The $\mathrm{pH}$ dependence of $\zeta$, determined in HFO suspensions and in the presence of different silicic acid amounts, is shown in Figure 3a. Clearly, the presence of silicic acid resulted in decreases in the $\zeta$ of HFO over a $\mathrm{pH}$ range from 2 to 9 . At $\mathrm{pH}<6$, HFO bears a positive surface, even in the presence of up to $1.5 \mathrm{mM}$ silicic acid. At $\mathrm{pH}<4$, relatively constant $\zeta$ of $20,19,17$, and $15 \mathrm{mV}$ was observed at silicic acid concentrations of 0 , $0.5,1.0$, and $1.5 \mathrm{mM}$, respectively. Substantial decreases in $\zeta$ were observed at $\mathrm{pH}$ 5-9. A pH change from 5 to 9 resulted in $\zeta$ decreases from 20 to $-16,19$ to $-19,17$ to -19 , and 15 to $-20 \mathrm{mV}$ for suspensions at silicic acid concentrations of $0,0.5,1.0$ and $1.5 \mathrm{mM}$, respectively. Under each $\mathrm{pH}$ condition $<10$, silicic-acid-amended HFO suspensions consistently exhibited lower $\zeta$ compared to pure HFO (prepared in deionized water). The charge reversal point (i.e. iep) was at $\mathrm{pH} 7.5$ for pure HFO, while lower iep values (7.0, 6.4, and 6.2) were found for silicic-acidamended HFOs. At $\mathrm{pH}>10$, $\zeta$ was approx. $17 \mathrm{mV}$ and no notable difference was observed among silicic acid concentrations. In this way, by shifting the HFO iep to lower $\mathrm{pH}$ values, silicic acid can be seen to change the aggregation properties of HFO.

The aggregation of pure $\mathrm{HFO}$ in the presence of silicic acid at 3 different concentrations as a function of $\mathrm{pH}$ is illustrated in Figure $3 \mathrm{~b}$. For pure HFO, $d_{h}$ increased over a $\mathrm{pH}$ range of 2 to 8 , and decreased at $\mathrm{pH}>8$. At $\mathrm{pH} 8$, a peak aggregation was observed in which $d_{h}$ reached $6700 \mathrm{~nm}$. Upon adsorption of silicic acid, the $d_{h}$ for HFO suspensions decreased and peak aggregation shifted to lower pHs. Maximum $d_{h}$ values $(5200,4700$, and $4300 \mathrm{~nm})$ were found at $\mathrm{pH} 7.0,6.3$, and 6.2 in the presence of silicic acid at concentrations of $0.5,1.0$, and $1.5 \mathrm{mM}$, respectively. 
Nguyen Ngoc Minh, Flynn Picardal/Vietnam Journal of Earth Sciences 38 (2016)

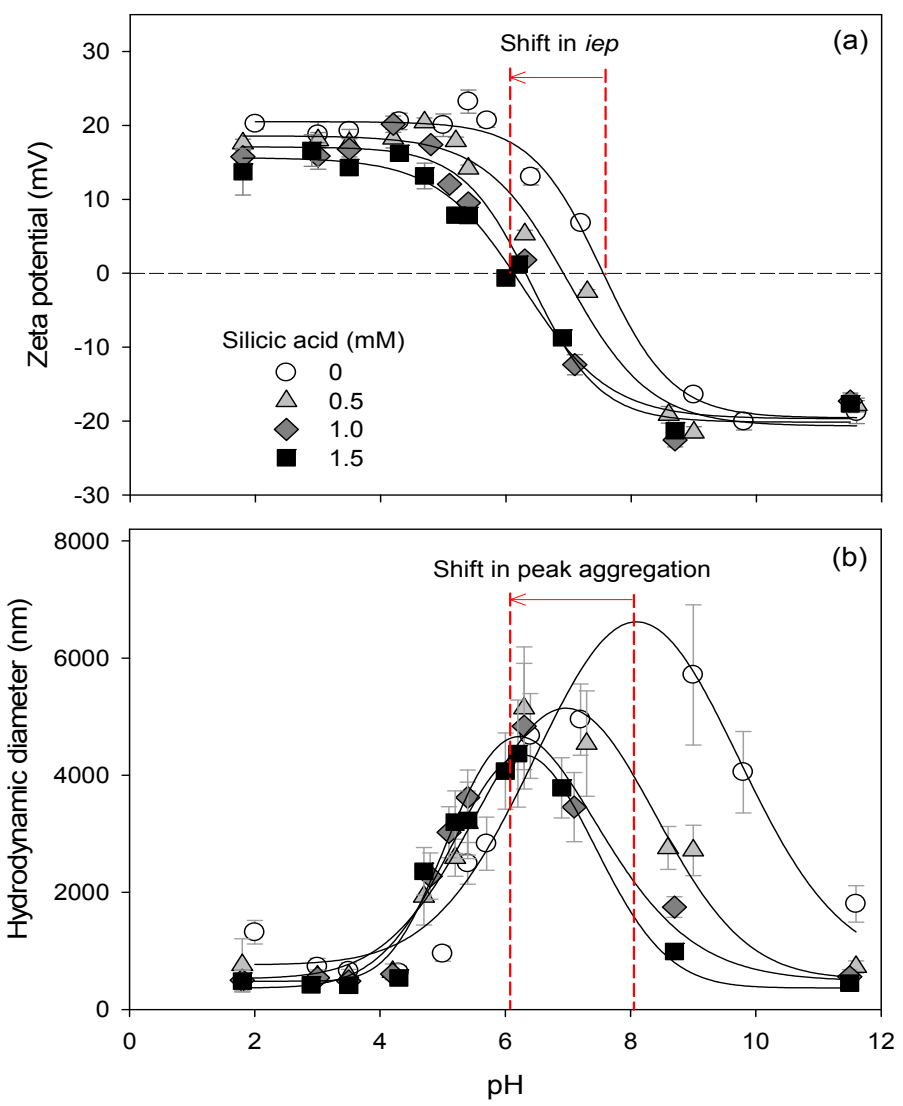

Figure 3. Zeta potential (a) and hydrodynamic radius (b) measured for HFO as a function of $\mathrm{pH}$ in the presence of $0.05 \mathrm{M} \mathrm{NaCl}$ as the background electrolyte. Error bars depict changes in hydrodynamic diameter of HFO aggregates measured at minute intervals over a $20 \mathrm{~min}$ period

Aggregation and $\zeta$ measurements of HFO at $\mathrm{pH} 6$ as a function of ionic strength for four systems that vary in silicic acid concentrations are shown in Figure 4. Positive $\zeta$ values were observed across the range of ionic strength from 0.0005 to $0.5 \mathrm{M}$, but $\zeta$ became less positive upon addition of silicic acid (Figure $4 a)$. With an increase in ionic strength from 0.0005 to $0.5 \mathrm{M}, \zeta$ decreased from 24.7 to $11.6,23.5$ to $5.2,17.5$ to 6.6 , and 8.3 to 4.9 $\mathrm{mV}$ for suspensions containing silicic concentrations of $0,0.5,1.0$, and $1.5 \mathrm{mM}$, respectively. These decreases in $\zeta$ are the probable explanation for the acceleration of HFO aggregation observed when ionic strength was increased. For suspensions with silicic acid concentrations of $0,0.5$, and 1.0 $\mathrm{mM}$, increasing ionic strength resulted in strong aggregation of HFO (Figure $4 \mathrm{~b}$ ). With a change of ionic strength from 0.0005 to 0.1 $\mathrm{M}, d_{h}$ values increased from 560 to 3510,770 to 2870 , and 1970 to $3510 \mathrm{~nm}$ for suspensions containing silicic concentrations of $0,0.5$, and $1.0 \mathrm{mM}$, respectively. In the presence of 1.5 $\mathrm{mM}$ silicic acid, $d_{h}$ was relatively high at low IS and no clear change in $d_{h}$ was seen as IS was increased from 0.0005 to $0.5 \mathrm{M}$. At a range of ionic strength from 0.1 to $0.5 \mathrm{M}$, only minor differences in $d_{h}$ were observed for different silicic acid concentrations. 
Vietnam Journal of Earth Sciences, 38(4), 345-355

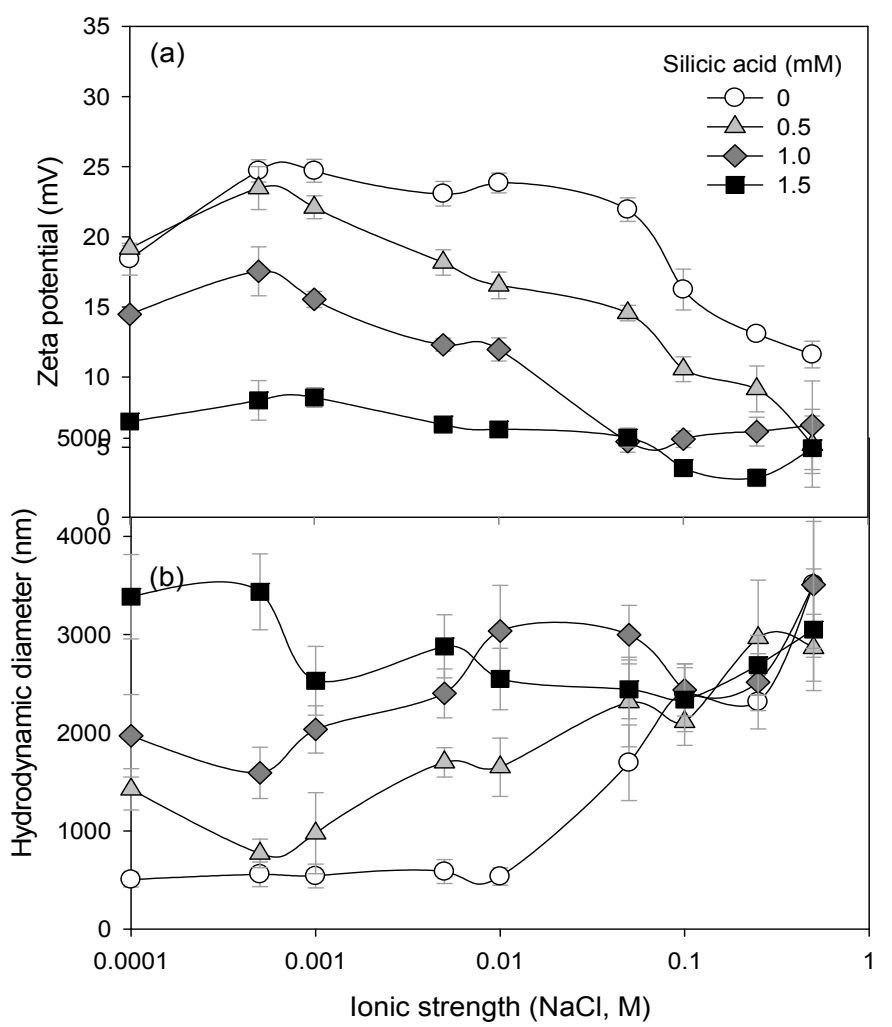

Figure 4. Zeta potential (a) and hydrodynamic radius (b) measured for HFO as a function of ionic strength in the presence of $0.05 \mathrm{M} \mathrm{NaCl}$ as the background electrolyte. Error bars illustrate the changes in hydrodynamic diameter of HFO aggregates measured every minute over a $20 \mathrm{~min}$ period

\subsection{Colloidal stability}

A 3D-graph with color gradient and mesh representing the amount of suspended colloids remaining in suspension (Figure 5) illustrates the aggregation of $\mathrm{HFO}$ in the presence of the silicic acid as a function of $\mathrm{pH}$. At $\mathrm{pH}<3$, HFO completely dissolved within a few hours. This was due to the high solubility of fine $\mathrm{HFO}$ particles in acidic condition as reported by Lindsay (1979) and Kuma et al. (1992). At $\mathrm{pH}>3$, the amphoteric properties of HFO were apparent, with HFO dispersed when bearing positive or negative surface charges, and aggregated around its iep. After $24 \mathrm{~h}$, three different statuses of the HFO suspensions could be observed: steric stabilization $(\%$ colloid $>90)$, aggregation $(\%$ colloid $<10)$, and transition status $(10<\%$ colloid $<90$ ). Aggregation of HFO appears highly dependent on $\mathrm{pH}$, and the effect of silicic acid varies within the $\mathrm{pH}$ range. At $\mathrm{pH}$ $<5.5$, increases in silicic acid concentration did not have a clear effect on HFO aggregation. The stable dispersion was observed across the range of silicic acid concentration from 0 to $1.5 \mathrm{mM}$. Aggregation status for all silicic acid concentrations occurred in the $\mathrm{pH}$ range from 5.5 to 7.5 . At $\mathrm{pH}>7.5$, HFO suspension status ranged from steric stabilization to aggregation depending on the silicic acid concentration. The silicic acid concentration of $0.8 \mathrm{mM}$ or higher resulted in a stable dispersion, whereas aggregation was favored at silicic acid concentrations below $0.8 \mathrm{mM}$. 
Nguyen Ngoc Minh, Flynn Picardal/Vietnam Journal of Earth Sciences 38 (2016)

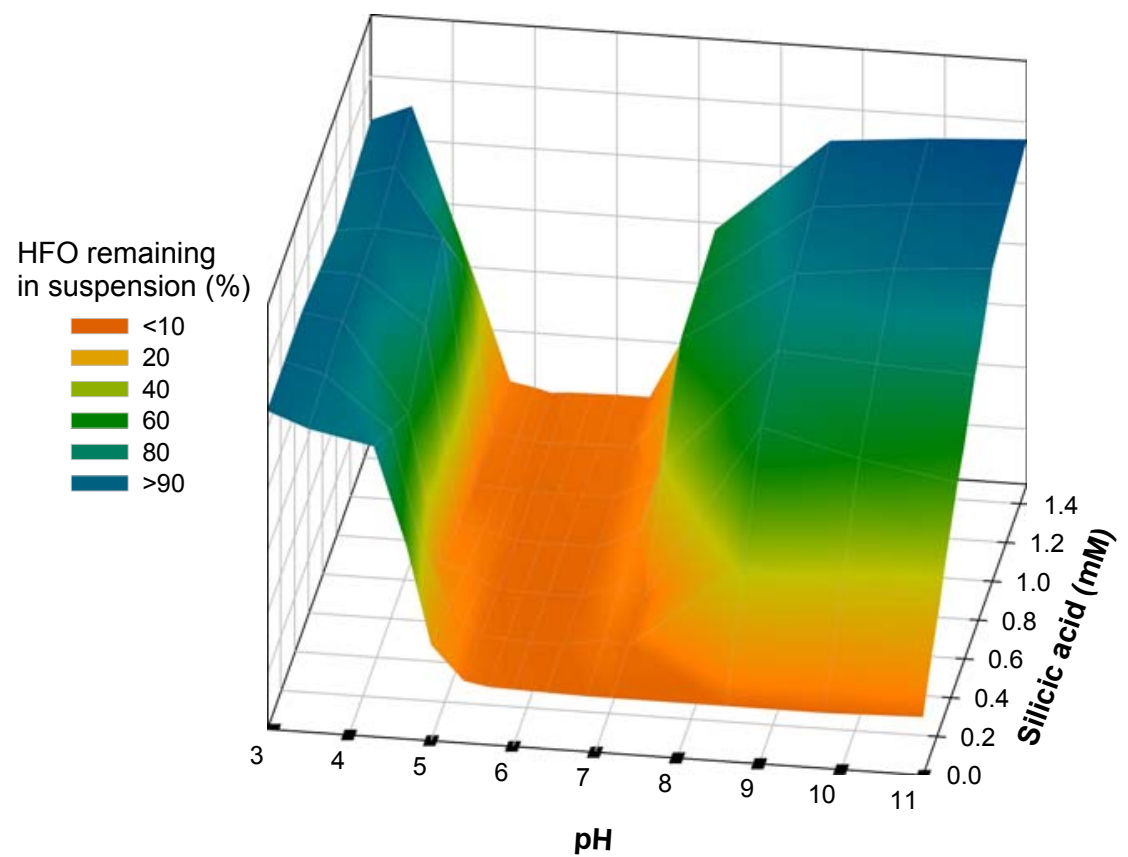

Figure 5. 3D graph created from the transmission data of the HFO suspension as functions of $\mathrm{pH}$ and silicic acid concentration, established after $24 \mathrm{~h}$. Values shown for the \% of HFO remaining in suspension include the HFO dissolved at low $\mathrm{pH}$ as described in the text

\section{Discussion}

In natural waters, silicic acid occurs almost exclusively in the form of the monomer $\left(\mathrm{Si}(\mathrm{OH})_{4}\right)$ or dimer $\left(\mathrm{Si}_{2} \mathrm{O}_{2}(\mathrm{OH})_{5}^{-}\right)$(Svensson et al., 1986; Dietzel, 2000). Variation in protonation/deprotonation and/or polymeric condensation can potentially yield other dissolved species (e.g. oligomeric silicic acids) (Iler, 1979; Dove and Rimstidt, 1994; Davis et al., 2002). pH and ionic strength can affect transformation of these species by changing their degree of protonation or deprotonation and resultant charge (Icopini et al., 2005). Our experiments at $0.05 \mathrm{M} \mathrm{NaCl}$ ionic strength (Figure 2) demonstrate that the surface charge of silicic acid suspensions changes significantly depending upon its concentration and $\mathrm{pH}$. At $\mathrm{pH}<6, \zeta$ is close to a zero-charge point for silicic acid suspensions at a concentration range of 0.5 to $1.5 \mathrm{mM}$, indicating almost complete protonation. This result is consistent with previous findings (Dietzel, 2000) in which silicic acid was reported to be neutral at acidic pHs. At $\mathrm{pH}>6$, negative charges can develop from the formation of polymeric silicic acid nanoparticles (Iler, 1979; Svensson et al., 1986; Dietzel, 2000), followed by deprotonation under alkaline condition (Icopini et al., 2005). At $\mathrm{pH}>6, \zeta$ decreases as silicic acid deprotonates, but increases again in extreme alkaline $\mathrm{pH}$ with a high concentration of $\mathrm{Na}^{+}$ion in solution, possibly due to $\mathrm{Na}^{+}$adsorption. When silicic acid deprotonates, its adsorption onto $\mathrm{Fe}$ oxides through ligand exchange (Hiemstra et al., 2007) could be a consequence. Therefore, as an adsorbing species, silicic acid could modify surface charge and affect the colloidal stability of HFO.

The iep of silicic-acid-amended HFO was observed at $\mathrm{pH} 7.5$ (Figure 3a), and peak aggregation was also observed near this $\mathrm{pH}$ 
Vietnam Journal of Earth Sciences, 38(4), 345-355

value (Figure 3b). This overlap suggests that aggregation of $\mathrm{HFO}$ is manipulated by neutralization of the net charge at the iep. Since electrostatic repulsion is minimized at the iep, aggregation can be induced since attractive Van der Waals forces prevail (Cornell and Schwertmann, 1996). At $\mathrm{pH}$ levels below the iep of 7.5, HFO appeared as positively charged particles due to the presence of protonated $\mathrm{Fe}-\mathrm{OH}_{2}{ }^{+}$groups on its surface (Figure 3a). These protonated groups can serve as positive charges and support an interaction with either anions or neutral substances in the surrounding solution (Lützow et al., 2006; Hiemstra et al., 2007). Adsorption of silicic acid onto HFO lowered the $\zeta$ of HFO and shifted the iep of HFO to lower $\mathrm{pH}$ values, enabling HFO to aggregate at lower $\mathrm{pH}$ as illustrated in Figure 3b. Above the iep of 7.5, HFO became negatively charged as $\mathrm{Fe}-\mathrm{OH}_{2}{ }^{+}$groups were converted to $\mathrm{Fe}^{-} \mathrm{O}^{-}$groups. Dispersion of HFO in response to increases in $\mathrm{pH}$ resulted from the enhancement of repulsive forces between particles in the aqueous system. The presence of the deprotonated silicic acid may serve to increase negative charges for suspensions (Figure 3a), which in turn facilitates dispersion of HFO (Figure 3b). Aside from $\mathrm{pH}$, ionic strength can also strongly affect aggregation of HFO by changing $\zeta$ (Figure 4). Increasing ionic strength resulted in decreases in $\zeta$ (less positive) and electronic double layer thickness, favoring aggregation. In experiments on aggregation of $\mathrm{HFO}$ at $\mathrm{pH} 6$, no effect of silicic acid was clearly observable at high ionic strength $([\mathrm{NaCl}]>0.1 \mathrm{M})$. In contrast, silicic acid showed a clear effect as an aggregation enhancer at low ionic strength $([\mathrm{NaCl}]<0.1 \mathrm{M})$.

The trend in which aggregation of HFO occurred near the iep (pH from 5.5 to 7.5) was also observed in the "colloidal stability" experiments, as shown in Figure 5. However, the effect of silicic acid was more evident in alkaline solutions $(\mathrm{pH}>7)$, for which both aggregation and dispersion states of HFO were observed. In the presence of silicic acid up to $0.4 \mathrm{mM}$, HFO was still aggregated even at very high $\mathrm{pH}$. This result could be due to a strong effect of sorption of $\mathrm{Na}^{+}$ions resulting in a decrease in $\zeta$ as shown in Figure 3a, as well as reduction of the double layer thickness. Consequently, HFO particles can come closer together, which favors aggregation. Increasing silicic acid resulted in a stabilizing effect on the HFO dispersion in which the region of aggregation was significantly reduced at higher $\mathrm{pHs}$. With an increase of silicic acid to $0.8 \mathrm{mM}$, the full dispersion was observed over the $\mathrm{pH}$ range from 7.5 to 11. In contrast, the dispersion state was stabilized at $\mathrm{pH}<5.5$, and the presence of silicic acid did not result in aggregation in the HFO suspension. Generally, the presence of silicic acid expanded the dispersion zone of HFO as depicted in Figure 6, which implies that silicic might affect a number of processes involving $\mathrm{HFO}$ in nature, including colloid mobilization, coagulation, and iron sequestration.

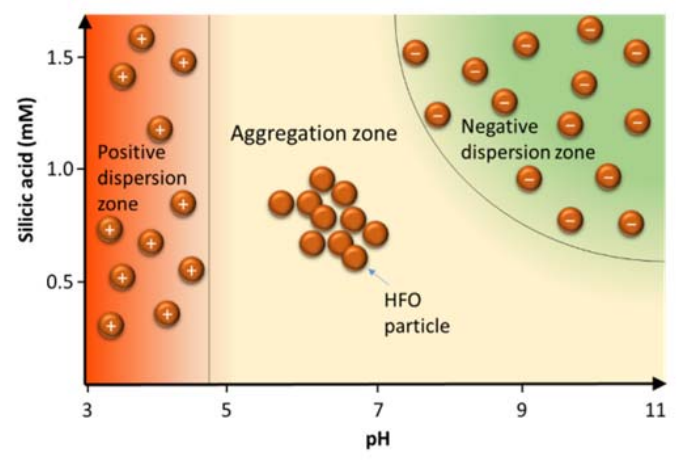

Figure 6. Schematic description of colloidal behavior of $\mathrm{HFO}$ in the presence of silicic acid

\section{Conclusion}

Silicic acid was observed to affect surface charge and aggregation of HFO over a wide 
Nguyen Ngoc Minh, Flynn Picardal/Vietnam Journal of Earth Sciences 38 (2016)

range of $\mathrm{pH}$ levels and ionic strength. Upon adsorption, it is likely that silicic acid lowers $\zeta$ and decreases iep, allowing HFO to aggregate at lower $\mathrm{pH}$ levels. The maximum aggregation of HFO under the influence of silicic acid was observed at $\mathrm{pH}$ 5.5-7.5, which is a typical $\mathrm{pH}$ value of many aqueous systems and soils. This finding suggests that silicic acid can play an important role for HFO transport in water and in the accumulation of particulate HFO in soil horizons. Understanding the effect of silicic acid on HFO aggregation is also helpful in supporting a deeper knowledge of the mobility of the pollutants loaded by $\mathrm{Fe}$ colloids in natural aqueous environments.

\section{Acknowledgements}

This research is funded by Vietnam National Foundation for Science and Technology Development (NAFOSTED) under grant number "105.08-2015.01". We would like to thank Ph.D. student Thuy T.H. An, SPEA, Indiana University for her support to prepare the HFO sample and help in imaging with TEM. We are grateful to Ms. Elisabeth Andrews for editorial assistance.

\section{References}

Combes, J.M., Manceau, A., Calas, G., Bottero, J.Y., 1989. Formation of ferric oxides from aqueous solutions: A polyhedral approach by X-ray absorption spectroscdpy: I. Hydrolysis and formation of ferric gels. Geochimica et Cosmochimica Acta 53, 583-594.

Cornell, R.M., Schwertmann, U., 1996. The iron oxides: structure, properties, reactions, occurence and uses. VCH, Weinheim and New York.

Davis, C.C., Chen, H.-W., Edwards, M., 2002. Modeling Silica Sorption to Iron Hydroxide. Environmental Science \& Technology 36, 582-587.

Dietzel, M., 2000. Dissolution of silicates and the stability of polysilicic acid. Geochimica et Cosmochimica Acta 64, 3275-3281.

Dove, P.M., 1995. Kinetic and thermodynamic controls on silica reactivity in weathering environments.
Reviews in Mineralogy and Geochemistry 31, 235-290.

Dove, P.M., Rimstidt, J.D., 1994. Silica water interactions - In silica reviews in mineralogy. Mineral Society of America, 29, 259-307.

Epstein, E., 2001. Silicon in plants: facts vs. concepts. In: Datnoff, L.E., Snyder, G.H. and Korndörfer, G.H. (Ed.), Silicon in Agriculture. Elsevier, Amsterdam, pp. 1-16.

Fortin, D., Langley, S., 2005. Formation and occurrence of biogenic iron-rich minerals. Earth-Science Reviews 72, 1-19.

Hiemstra, T., Barnett, M.O., van Riemsdijk, W.H., 2007. Interaction of silicic acid with goethite. Journal of Colloid and Interface Science 310, 8-17.

Holthoff, H., Egelhaaf, S.U., Borkovec, M., Schurtenberger, P., Sticher, H., 1996. Coagulation rate measurements of colloidal particles by simultaneous static and dynamic light scattering. Langmuir 12, 5541-5549.

Hunter, R.J., 1981. Chapter 3 - The calculation of zeta potential. Zeta potential in colloid science. Academic Press, pp. 59-124.

Icopini, G.A., Brantley, S.L., Heaney, P.J., 2005. Kinetics of silica oligomerization and nanocolloid formation as a function of $\mathrm{pH}$ and ionic strength at $25^{\circ} \mathrm{C}$. Geochimica et Cosmochimica Acta 69, 293-303.

Iler, R.K., 1979. The chemistry of silica. WileyInterscience, New York.

Karathanasis, A.D., 2002. Mineral equilibria in environmental soil systems, in: Soil Mineralogy with environmental applications. Soil Science Society of America, 109-151.

Kretzschmar, R., Holthoff, H., Sticher, H., 1998. Influence of $\mathrm{pH}$ and humic acid on coagulation kinetics of kaolinite: A dynamic light scattering study. Journal of Colloid and Interface Science 202, 95-103.

Kuma, K., Nakabayashi, S., Suzuki, Y., Matsunaga, K., 1992. Dissolution rate and solubility of colloidal hydrous ferric oxide in seawater. Marine Chemistry 38, 133-143.

Lagaly, G., Schulz, O., Ziemehl, R., 1997. Dispersionen und emulsionen: Eine Einführung in die Kolloidik feinverteilter Stoffe einschließlich der Tonminerale. Steinkopff Verlag, Darmstadt. 


\section{Vietnam Journal of Earth Sciences, 38(4), 345-355}

Li, H., Shan, C., Zhang, Y., Cai, J., Zhang, W., Pan, B., 2016. Arsenate adsorption by hydrous ferric oxide nanoparticles embedded in cross-linked anion exchanger: Effect of the host pore structure. ACS Applied Materials \& Interfaces 8, 3012-3020.

Lindsay, W.L., 1979. Chemical equilibria in soils. Wiley, New York.

Lützow, M.v., Kögel-Knabner, I., Ekschmitt, K., Matzner, E., Guggenberger, G., Marschner, B., Flessa, H., 2006. Stabilization of organic matter in temperate soils: mechanisms and their relevance under different soil conditions - a review. European Journal of Soil Science 57, 426-445.

Mori, Y., Togashi, K., Nakamura, K., 2001. Colloidal properties of synthetic hectorite clay dispersion measured by dynamic light scattering and small angle X-ray scattering. Advanced Powder Technology 12, 45-59.

Nguyen Ngoc Minh, Dultz S., Tran Thi Tuyet Thu, Bui Thi Kim Anh, 2013. Effect of anions on dispersion of a kaolinitic soil clay: A combined study of dynamic light scattering and test tube experiments. Geoderma 209-210, 209-213.

Pike, E.R., Abbiss, J.B., 1997. Light scattering and photon correlation spectroscopy. Springer Science + Business Media, B.V.

Rothbaum, H.P., Rohde, A.G., 1979. Kinetics of silica polymerization and deposition from dilute solutions between 5 and $180^{\circ} \mathrm{C}$. Journal of Colloid and Interface Science 71, 533-559.

Sommer, M., Kaczorek, D., Kuzyakov, Y., Breuer, J., 2006. Silicon pools and fluxes in soils and landscapes-a review. Journal of Plant Nutrition and Soil Science 169, 310-329.

Spadini, L., Schindler, P.W., Charlet, L., Manceau, A., Vala Ragnarsdottir, K., 2003. Hydrous ferric oxide: evaluation of Cd-HFO surface complexation models combining $\mathrm{CdK}$ EXAFS data, potentiometric titration results, and surface site structures identified from mineralogical knowledge. Journal of Colloid and Interface Science 266, 1-18.

Svensson, I.L., Sjoberg, S., Ohman, L.O., 1986. Polysilicate equilibria in concentrated sodium silicate solutions. J. Chem. Soc., Faraday Trans. 182, 3635-3646.

Towe, K.M., Bradley, W.F., 1967. Mineralogical constitution of colloidal "hydrous ferric oxides". Journal of Colloid and Interface Science 24, 384-392.

Wonisch, H., Gérard, F., Dietzel, M., Jaffrain, J., Nestroy, O., Boudot, J.P., 2008. Occurrence of polymerized silicic acid and aluminum species in two forest soil solutions with different acidity. Geoderma 144, 435-445. 